\title{
Finite element simulation of twist forming process to study twist springback pattern
}

\author{
M. N. Nashrudin ${ }^{1}$, and A. B. Abdullah ${ }^{1, *}$ \\ ${ }^{1}$ Metal Forming Research Laboratory, School of Mechanical Engineering, Universiti Sains Malaysia, \\ 14300 Nibong Tebal, Pulau Pinang, Malaysia. Phone: 604-5996332, Fax: 604-5941025
}

\begin{abstract}
Springback is one of the most common defects found in the metal forming of automotive parts. There are three conditions which can be considered as springback i.e. flange angle change, sidewall curl and twist springback and among them, twist springback is the most complicated problem. This study will focuses on the development of finite element simulation model of the twist forming process. The main aim of this project is to investigate the parameters that may affect the twist springback. Few parameters including twist angle, hardening constant and thickness are explored using finite element (FE) software ANSYS Workbench (16.0). The rectangular mild strips are used to form the twist forming. The standard material properties and stress-strain curve of mild steel had been used to get the springback prediction. The results of springback were measured by the difference of the bending angles before and after unloading process. The results were then be validated with the research made of Dwivedi et al., (2002). The results show that the springback angle reduces as the thickness of strips are increased and also as the angle of twist increases.
\end{abstract}

\section{Introduction}

In automotive industries, metal forming is the main process used in manufacturing process. The raw material is deformed plastically to obtain required shape and size. Examples of the process are forging, rolling, extrusion, sheet metal forming and hydro forming. Usually the primary shape of a car is created by plastically deforming the material. The dimension must be precise to assemble another parts into it. In every industry, quality and productivity are vital issues as it is related to the cost of manufacturing. Every forming process, there are defects can be occurred and one of it is springback. The defects need to be controlled.

Springback occurs after forming that change the part to the undesirable shape [1]. The cause of it is due to the disappearance of the elastic deformation after removing the external load and the final shape is different from the die shape [2]. It happens toward the end of plastic deformation[3]. The effects of springback are it can bring the undesirable shape change, leads to some difficulties in assembly, decrease the material mechanical properties

\footnotetext{
Corresponding author: mebaha@usm.my
} 
and causes geometrical and unreliability of sheet metal after forming [2,3]. The springback also affected by the applied tension, the bending radius and the mechanical properties of material [5]. There are 3 general types of springback which are angular change, sidewall curl and twist springback [4]. Among of them, twist springback is the most complicated and it will be focused in this study.

Twist springback involved twisting and bending that considered as one of the major geometrical defect in strip metal forming. It is tendency of twisted part return to its original shape due to the elastic recovery when unloading [6]. The unbalanced elasticplastic deformation and residual stress after the forming process are the causes of the twist springback [7]. When the twist keeps increasing, the non-recoverable plastic deformation increases and the recoverable elastic deformation keeps decreasing [8]. Springback in angle of twist depends on the point on the curve where unloading is initiated and the shape of the elastic unloading line [9]. There are many automotive parts that can exhibit twist springback such as B pillar and twist rail [10].

In this study, the development of finite element simulation model of twist forming process will be focused. The parameters that may affect twist springback are the main investigation of this project. The result will be validated with the research made of Dwivedi et al., (2002) [8]. From the previous research by [8], an analysis for twist forming process has been made using experimental method. The parameters studied for this method will be compared by using finite element simulation method on this research. Then validation can be made that finite element simulation method is relevant to be used to predict springback percentage. All parameters will be used same as the previous research by Dwivedi et al., (2002).

\section{Methodology}

\subsection{Finite element simulation}

In this study, twist forming process was simulated using finite element (FE) software ANSYS Workbench (16.0). Figure 1 shows the model and boundary condition of mild steel strip that undergo twist forming.

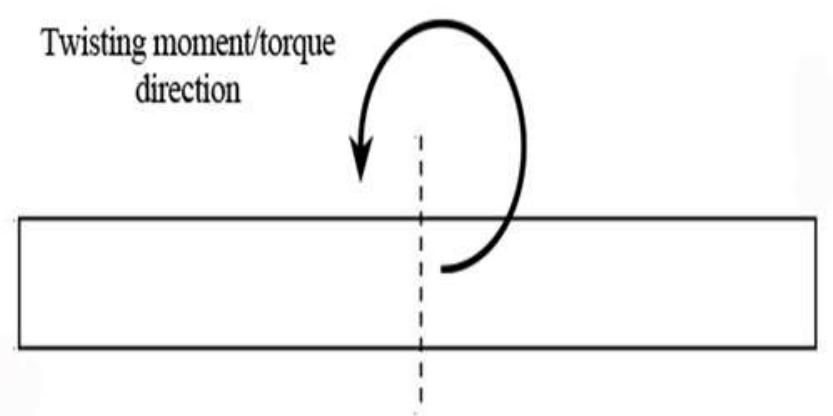

\section{Zero displacement (dotted line)}

Fig. 1. Model and boundary conditions for simulation process.

The rectangular mild steel strips were modeled in SolidWorks with thickness of 2.2 and $3.2 \mathrm{~mm}$, width of $25.4 \mathrm{~mm}$ and length of $178 \mathrm{~mm}$. Then the strips were modeled in ANSYS to undergo simulation for springback prediction. The center of the strip are fixed and 
twisting moment or torque are applied at both ends. Table 1 list the material properties of mild steel used for simulation process.

Table 1. Material properties of mild steel used.

\begin{tabular}{|c|c|}
\hline Material properties & Value \\
\hline Elastic modulus & $210 \mathrm{GPa}$ \\
\hline Poisson's ratio & 0.29 \\
\hline Modulus of rigidity & $82 \mathrm{GPa}$ \\
\hline Density & $7800 \mathrm{~kg} / \mathrm{m}^{3}$ \\
\hline Yield strength & $200 \mathrm{MPa}$ \\
\hline
\end{tabular}

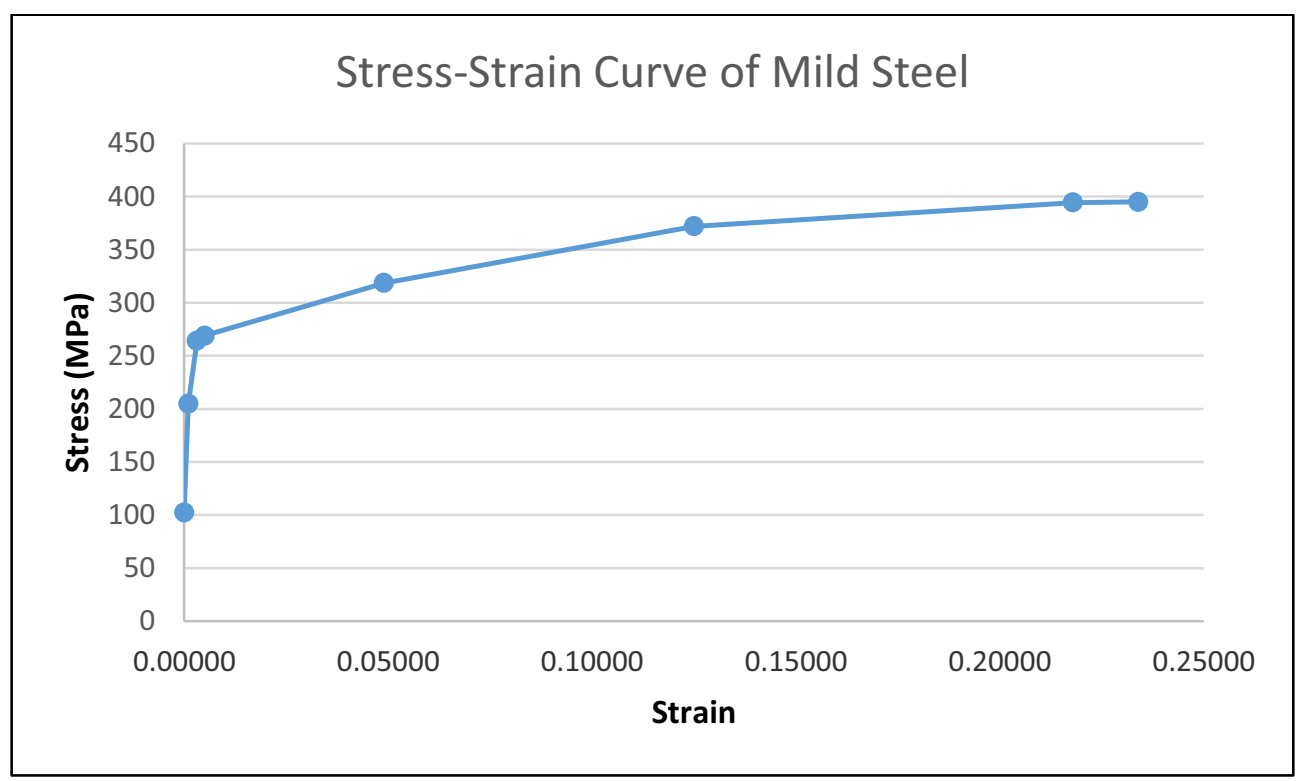

Fig. 2. Stress-strain curve of mild steel.

\subsection{Analysis of springback measurement}

From the front view, the angle for both before and after of springback are shown in Figure 3. The value of springback angle can be expressed as the change of bending angle [11].

$$
\Delta \Theta=\Theta_{\mathrm{o}}-\Theta_{\mathrm{f}}
$$

Where $\Theta_{\mathrm{o}}$ and $\Theta_{\mathrm{f}}$ are the bending angles before and after unloading process, respectively. 


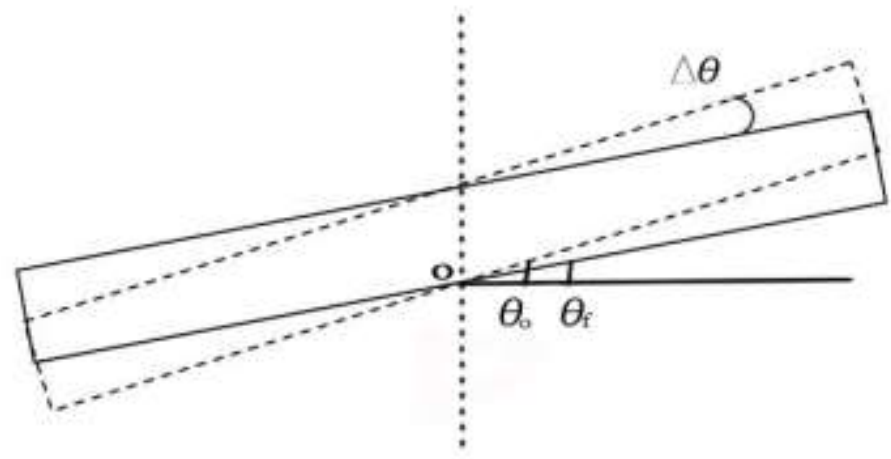

Fig. 3. Angle before and after springback.

\section{Results and discussion}

In this study, simulations were made to compare the result with the result published by Dwivedi et al., (2002). The parameters that have been used were different twist angle, the different thickness of strips and the strain hardening index, $n$ of $1 / 3$ for mild steel with material properties stated on Table 1 . The results show the percentage difference between the both results are quite large but the curve patterns are similar. Pattern of springback in percentage against thickness are shown in Figure 4, while relationship of springback in percentage against twist angle in Figure 5 and 6.

Based on the result, the springback angle reduces as the thickness of strips are increased. Higher plastic zone is created at higher sheet thickness and result to lower springback angle. The value of angle of twist also gives significant effect to springback angle. The springback angle will decrease as the angle of twist increases. Twist angle is more sensitive to process parameters and material direction as well as the materials. Torque slows down when the twist increases and result to lower springback angle.

State that the result is below $10 \%$ and $36 \%$ of deviation for the thickness of $2.2 \mathrm{~mm}$ and $3.2 \mathrm{~mm}$ respectively. This can be concluded that the validation is reliable since the percentage difference are quite low for $2.2 \mathrm{~mm}$ thickness. From research by [12], the deviation below $10 \%$ is considered low in springback cases. For $3.2 \mathrm{~mm}$ thickness, the deviation is quite large because of the twisting moment goes beyond the plastic region of the section. It may be reduced if more accurate material properties for stress-strain curve is obtained. Additional study about FE simulation also may improve the results. 


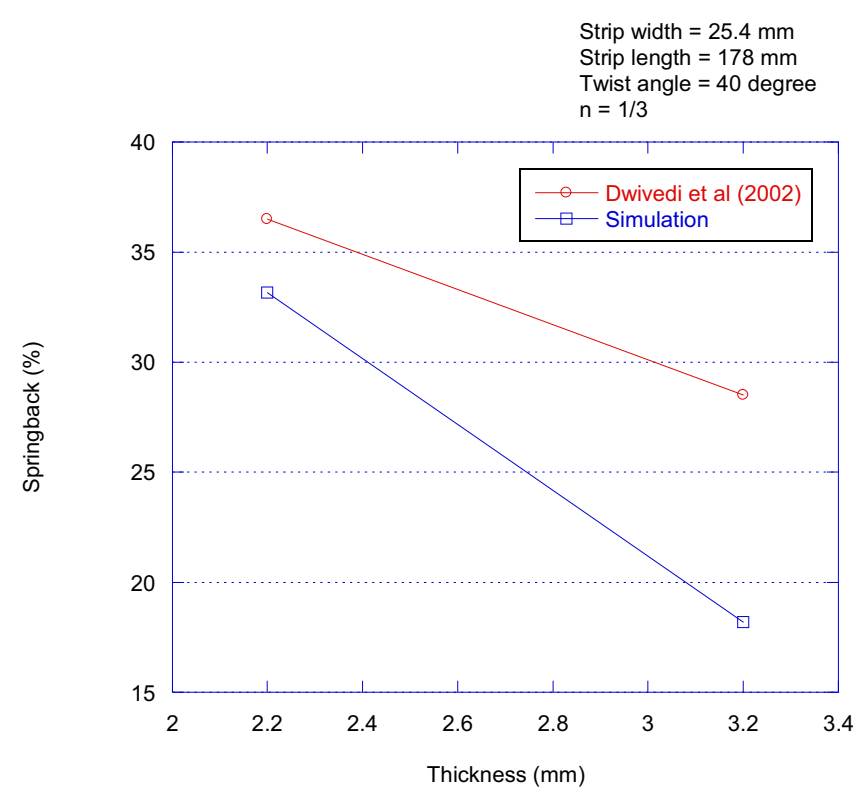

Fig. 4. Springback percentage against thickness for angle of twist of $40^{\circ}$.

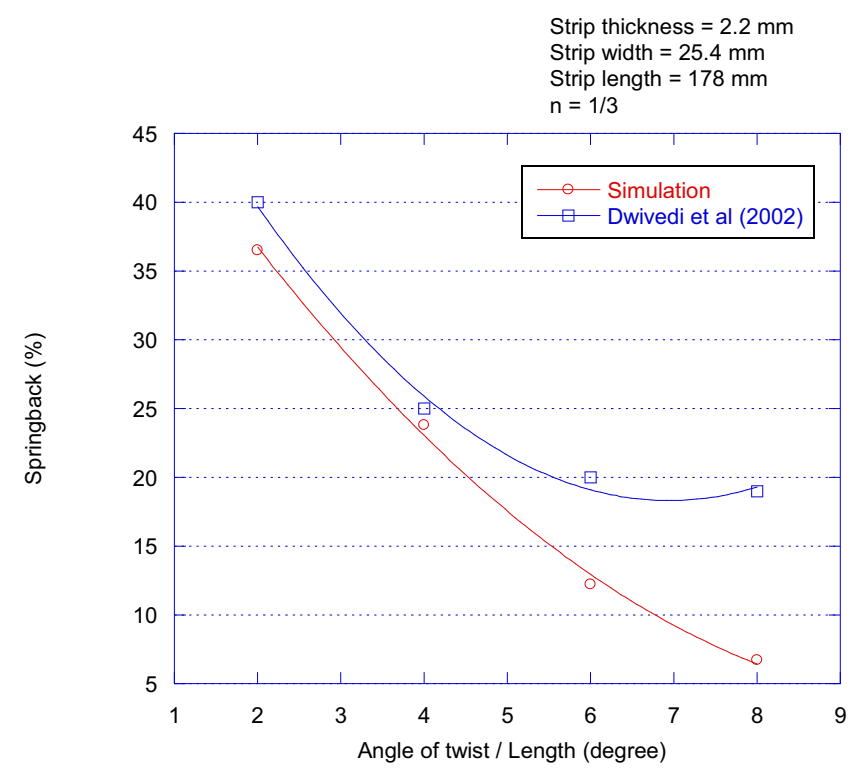

Fig. 5. Springback percentage against angle of twist for strip thickness of $2.2 \mathrm{~mm}$. 


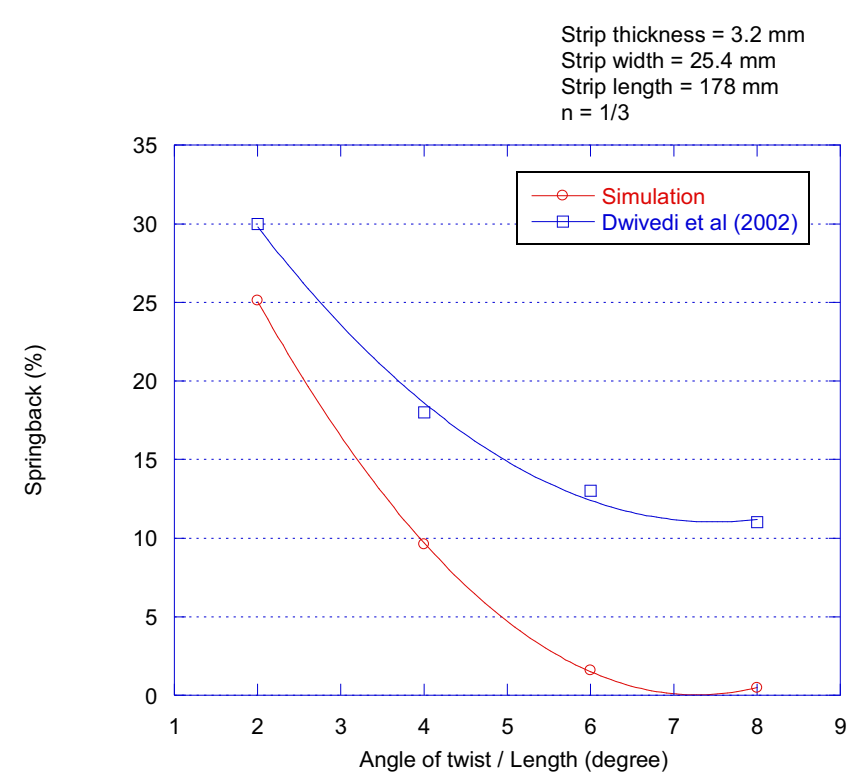

Fig. 6. Springback percentage against angle of twist for strip thickness of $3.2 \mathrm{~mm}$.

\section{Conclusions}

As a conclusion, the parameter of thickness of strips and angle of twist gave significant effect to the twist springback angle based on the results. The validation is accepted since the curve patterns are same and the deviation is low i.e. between the results for $2.2 \mathrm{~mm}$ thickness. For future work, the effect of another parameters to the twist springback angle will be explored using simulations and experiments.

The authors want to acknowledge Ministry of Higher Education for their sponsorship through Fundamental Research Grant Scheme (Acc. No. 203/PMEKANIK/6071308).

\section{References}

1. X. Xue, J. Liao, G. Vincze, J. Sousa, F. Barlat, and J. Gracio, "Modelling and sensitivity analysis of twist springback in deep drawing of dual-phase steel," Mater. Des., 90, pp. 204-217, (2016).

2. W. Jiang, B. Yang, X. Guan, and Y. Luo, "Bending and twisting springback prediction in the punching of the core for a lattice truss sandwich structure," Acta Metall. Sin. (English Lett.,. 26, no. 3, pp. 241-246, (2013).

3. S. Xu, K. Zhao, T. Lanker, J. Zhang, and C. T. Wang, "Springback prediction, compensation and correlation for automotive stamping," AIP Conf. Proc., 778 A, pp. 345-352, (2005).

4. W.Y.D. Yuen, "Springback in the Stretch-Bending of Sheet Metal with Non-Uniform Deformation,” J. Mater. Process. Technol., 22, pp. 1-20, (1990).

5. M. Ueda, K. Ueno, and M. Kobayashi, "A study of springback in the stretch bending 
of channels," J. Mech. Work. Technol., 5, no. 3-4, pp. 163-179, (1981).

6. A. B. Abdullah and Z. Samad, "Measurement of Twist Springback on AA6061-T6 Aluminum Alloy Strip - A Preliminary Result," Appl. Mech. Mater.,. 699, pp. 44-48, (2014).

7. X. Xue, J. Liao, G. Vincze, and J. Gracio, "Modelling of mandrel rotary draw bending for accurate twist springback prediction of an asymmetric thin-walled tube," Procedia Eng., 81, pp. 2177-2183, (2014).

8. J. P. Dwivedi, S. K. Shah, P. C. Upadhyay, and N. K. Das Talukder, "Springback analysis of thin rectangular bars of non-linear work-hardening materials under torsional loading," Int. J. Mech. Sci., 44, no. 7, pp. 1505-1519, (2002).

9. N. K. T. J. P. Dwivedi, A.N. Singh, Sohan Ram, "Springback analysis in torsion of rectangular strips," Pergamon Journals Ltd, 28, no. 8, pp. 505-515, (1986).

10. H. Li, G. Sun, G. Li, Z. Gong, D. Liu, and Q. Li, "On twist springback in advanced high-strength steels," Mater. Des., 32, no. 6, pp. 3272-3279, (2011).

11. J. Liao, X. Xue, M. G. Lee, F. Barlat, and J. Gracio, "On twist springback prediction of asymmetric tube in rotary draw bending with different constitutive models," Int. J. Mech. Sci., 89, pp. 311-322, (2014).

12. A. B. Abdullah, M. S. Salit, Z. Samad, K. H. MTandoor, and N. A. Aziz, "Twist springback measurement of autonomous underwater vehicle propeller blade based on profile deviation," Am. J. Appl. Sci., 10, no. 5, pp. 515-524, (2013). 